\title{
ANALISIS PEMILIHAN SUPPLIER MENGGUNAKAN METODE ANALYTIC HIERARCY PROCESS DAN TOPSIS (Studi Kasus: Perusahaan Kimia)
}

\author{
Zulfikar Alwasly ${ }^{1}$, Said Salim Dahdah ${ }^{2}$, Elly Ismiyah ${ }^{3}$ \\ ${ }^{1}$ Mahasiswa Teknik Industri, Fakultas Teknik, Universitas Muhammadiyah Gresik \\ ${ }^{2,3}$ Dosen Teknik Industri, Fakultas Teknik, Universitas Muhammadiyah Gresik Jl. Sumatera No. 101 \\ GKB-Gresik 61121, Jawa Timur, Indonesia \\ Email: zulfikar_170601@umg.ac.id, said_salim@umg.ac.id_.ismi_elly@umg.ac.id
}

\begin{abstract}
ABSTRAK
Sebuah perusahaan kimia dalam bidang usaha bahan kimia industri yang memproduksi barang-barang yang dibutuhkan oleh sebuah industri, baik agro, konstruksi dan lain-lain yang berhubungan dengan barang industri. Perusahaan ini mencoba melakukan penyesuaian dengan ikut mempertimbangakn risiko yang akan terjadi pada lingkungan untuk melakukan supplier selection dari bahan baku berupa kapur aktif. Sebagai perusahaan yang berhubungan dengan bahan kimia yang memiliki risiko pada lingkungan. Terdapat 5 supplier yang ada di perusahaan kimia ini. Penelitian ini ditujukan untuk mengetahui kriteria, subkriteria dan supplier yang terbaik dengan adanya pembobotan dan perangkingan yang termasuk kedalam cakupan multicriteria decision making $(M C D M)$. Dalam menentukan pembobotan terhadap kriteriadan subkriteria digunakan metode Analytic Hierarcy Process (AHP), dan untuk perangkingannya digunakan metode TOPSIS. Nilai yang digunakan berasal dari hasil kuesioner 3 responden. Hasil dari penelitian ini terdapat 5 kriteria dan 11 subkriteria. Dari hasil pembobotan menggunakan metode $A H P$ diketahui kriteria terbesar adalah kriteria kualitas sebesar 0,34 dan subkriterianya adalah kesesuaian spesifikasi sebesar 0,282 sedangkan dari rangking tertinggi menggunakan metode TOPSIS adalah supplier 4 dengan nilai preferensi 0,442064 yang memiliki jarak terdekat dari solusi ideal positif $(0,042202)$ dan jarak terjauh dari solusi ideal negatif $(0,053264)$ dibanding supplier lainnya.
\end{abstract}

Kata kunci: Supplier selection, MCDM, AHP, TOPSIS

\section{PENDAHULUAN}

Pada era yang tinggi akan ketidakpastian, samar-samar atau yang lebih dikenal dengan era VUCA (volatility, uncertainty, complexity, dan ambiguity) (Horney, Pasmore, \& O'Shea, 2010) yang menuntut perusahaan untuk menghadapi tantangan berupa menciptakan fleksibitas organisasi dalam beradaptasi secara cepat terhadap perubahan lingkungan bisnis dan keinginan konsumen (Sattar, 2016). Fleksibilitas tidak hanya pada proses manufatur tetapi terjadi pada rantai pasok yang ada di perusahaan yang berperan penting dalam keunggulan kompetitif perusahaan, dimana aliran material akan sangat mempengaruhi kinerja perusahaan ( $\mathrm{Sa}$ ńchez \& Pe'rez, 2006).

Untuk menjaga kinerja perusahaan pada rantai pasok dapat dengan pemilihan supplier yang menjadi proses strategis pada hubungan dyadic antara supplier dengan pembeli yang lebih baik atau integrasi eksternal dengan memperkuat hubungan pembeli - supplier, agar dapat meningkatkan visibilitas rantai pasokan dan kemampuan mengatasi violatilitas permintaan yang tinggi. (Mukherjee, 2017).

Salah satu perusahaan dalam bidang Chemical Membutuhkan berbagai bahan, termasuk juga bahan pertambangan yang merupakan bahan tak terbaharukan yaitu kapur aktif. Pada situasi ini terkadang pihak supplier hanya menyediakan bahan yang terbatas tetapi pihak perusahaan memiliki standar nilai atau target tertentu yang mendorong pihak supplier untuk dapat memenuhi keinginan dari pihak perusahaan.

Untuk mencapai tujuan pemilihan supplier terbaik dengan banyaknya kriteria yang ada, maka multicriteria decision making (MCDM) telah menjadi subbidang riset operasi dan ilmu manajemen yang paling penting dan paling cepat berkembang. (Munier, Hontoria, \& JiménezSáez, 2019). MCDM telah di kembangkan untuk menangani pengukuran kriteria dari konflik yang berwujud atau tidak dan terhubung dengan kriteria yang akan menentukan ukuran alternatif keputusan, salah satu metode yang popular digunakan adalah Analytic Hierarcy Process (AHP) (Saaty \& Ergu, 2015).

Metode AHP adalah proses dalam mendapatkan skala relatif yang menggunakan penilaian atau data dari skala standar serta cara mengetahui operasi aritmatika selanjutnya pada skala tersebut untuk menghindari pemecahan angka yang tidak berguna (Saaty, How to make a Decision : The Analytic Hirarchy Process, 1990). 
Penggunaan metode AHP dapat memberikan bobot yang sesuai dengan penilaian seorang pembuat keputusan yaitu dengan cara membandingkan satu kriteria dengan kriteria lainnya atau dengan kata lain metode AHP dapat menyelesaikan suatu masalah yang kompleks dengan menyusunnya menjadi sebuah hierarki. (Saaty, The Analytical Hierarchy Process, Planning, Priority Resource Allocation, 1980) Dengan diketahui bobot dari masing-masing kriteria tersebut, bisa dijadikan bahan pertimbangan dalam memilih supplier.

Metode AHP memiliki kekurangan yaitu terlalu berisiko apabila hanya menggunakan metode AHP saja untuk memilih atau menentukan alternatif terbaik. Maka dari itu, metode AHP di kombinasikan dengan metode TOPSIS dengan alasan dapat menyelesaikan pengambilan keputusan secara praktis, karena memiliki konsep yang sederhana dan mudah dipahami, serta memiliki kemampuan dalam mengukur kinerja dari alternatif-alternatif keputusan. (Chamid \& Murti, 2017). Dengan kelebihan kombinasi metode AHP dan metode TOPSIS tersebut dapat digunakan dalam sistem pendukung pembuat keputusan.

\section{METODE PENELITIAN}

Penelitian ini membahas mengenai analisis alternatif supplier terbaik mengunakan kombinasi metode AHP dan metode TOPSIS. Pada penelitian ini peneliti mendapatkan data berupa angka atau data kualitatif yang diangkakan. Pada penelitian kuantitatif ini, pengumpulan datanya didapatkan dari penelitian lapangan yang berupa wawancara dan data hasil kuisioner yang didapatkan dari responden yang ditentukan sesuai dengan kebutuhan. Dalam penelitian ini tidak melakukan penelitian lapangan secara langsung dikarenakan kondisi yang belum memungkinkan untuk dilakukan

\section{LANGKAH-LANGKAH PENELITIAN}

Langkah - langkah yang dilakukan dalam melakukan penelitian ini adalah sebagai berikut:

1. Studi lapangan dan Studi literatur

Studi lapangan untuk mendefinisikan permasalahan mengenai supplier yang ada (Lima Junior, Osiro, \& Carpinetti, 2014). Pada studi lapangan ini dilakkan secara tidak langsung dengan berdasarkan data yang telah diberikan. Studi literatur sebagai dasar untuk menyelesaikan penelitian ini. Literatur yang digunakan mengenai pemilihan supplier menggunakan kombinasi metode AHP dan metode TOPSIS.

\section{Pengumpulan Data}

Pada penelitian ini, dilakukan pengumpulan data dengan cara wawancara kepada responden dan penyebaran kuesioner secara tidak langsung. Responden merupakan anggota dari bagian Pengadaan.

3. pengolahan data

Langkah-langkah metode AHP (Mukherjee, 2017):

a. Mendefinisikan masalah yang ada dan tentukan target atau capaian solusi yang diinginkan.

b. Mendefinisikan kriteria dan sub-kriteria untuk menyelesaikan target atau capaian yang di inginkan.

c. Menggunakan skala preferensi Saaty untuk membentuk matriks perbandingan berpasangan antar kriteria, antar subkriteria dan alternatif berdasakan hasil kuesioner 3 responden.

d. Menormalisasi hasil dari matriks perbandingan berpasangan yaitu dengan membagi nilai dari setiap elemen di dalam matriks yang berpasangan dengan nilai total dari setiap kolom.

e. Menghitung nilai eigen vector atau bobot dengan cara merata-rata jumlah baris dengan jumlah kriteria atau subkriteria.

f. Menghitung konsistensi indeks dan konsistensi rasio dari hasil perhitungan pembobotan untuk mengetahui validasi dari prroses pembuatan keputusan. dengan $\mathrm{CR}<0,1$ agar dapat dikatakan konsisten.

Hasil metode AHP digunakan sebagai input metode TOPSIS (Hwang \& Yoon, 1981). Berikut langkah-langkah Metode TOPSIS (Chamid \& Murti, 2017):

a. Membuat sebuah matriks keputusan.

$X=\begin{array}{cccccccc} & x_{1} & x_{2} & x_{3} & . & . & . & x_{n} \\ a_{1} & x_{11} & x_{12} & x_{13} & . & . & . & x_{1 n} \\ a_{2} & x_{21} & x_{22} & x_{23} & . & . & . & x_{2 n} \\ a_{3} & x_{31} & x_{32} & x_{33} & . & . & . & x_{3 n} \\ . & . & . & . & . & . & . & . \\ . & . & . & . & . & . & . & . \\ . & . & . & . & . & . & . & . \\ a_{m} & x_{m 1} & x_{m 2} & x_{m 3} & . & . & . & x_{m n}\end{array}$

b. Melakukan normalisasi matriks keputusan Elemen rij hasil dari normalisasi matriks keputusan menggunakan metode Euclidean length of a vector adalah :

keterangan:

$$
r_{i j}=\frac{x_{i j}}{\sqrt{\sum_{i=1}^{n} x_{i j^{2}}}}
$$

xij merupakan rating kinerja alternatif ke-i terhadap atribut ke-j 
rij adalah elemen dari matriks keputusan yang ternormalisasi.

c. Menentukan matriks keputusan yang memiliki bobot. Dengan bobot $\mathrm{W}=(\mathrm{w} 1, \mathrm{w} 2, \ldots \ldots, \mathrm{wn})$, maka normalisasi bobot matriks $\mathrm{V}$ adalah :

$\mathrm{V}=\left[\begin{array}{cccc}w_{1} r_{11} & w_{2} r_{12} & \ldots & w_{n} r_{1 n} \\ w_{1} r_{21} & & & \\ \cdot & & & \\ w_{1 r} m_{1} & w_{2} r_{m 2} & \ldots & w_{n} r_{m n}\end{array}\right]$

keterangan:

wj adalah bobot dari kriteria ke-j

yij adalah elemen dari matriks keputusan yang ternormalisasi terbobot

d. Menentukan solusi ideal positif dan solusi ideal negatif :

$$
\begin{aligned}
\mathrm{V}+ & =\left\{\max v i j|j € \mathrm{~J}, \min v i j| j € \mathrm{~J}^{\prime \prime},\right. \\
\mathrm{i} & =1,2,3, \ldots \ldots, \mathrm{m}\} \\
& =\{1+, v 2+, \ldots ., v n+\} \\
\mathrm{V}- & =\left\{\min v i j|j € \mathrm{~J}, \max v i j| j € \mathrm{~J}^{\prime \prime},\right. \\
\mathrm{i} \quad & =1,2,3, \ldots . ., \mathrm{m}\} \\
& =\{1, v 2, \ldots . ., v n-\}
\end{aligned}
$$

e. Menghitung separasi, $\mathrm{Si}+$ adalah jarak alternatif dari solusi ideal didefinisikan sebagai:

$$
S_{i}^{+}=\sqrt{\sum_{j=1}^{n}\left(v_{i j}-v_{j}^{+}\right)^{2}},
$$

dengan $\mathrm{i}=1,2, . . \mathrm{m}$

Dan jarak terhadap solusi negatif-ideal didefinisikan sebagai :

$$
S_{i}^{-}=\sqrt{\sum_{j=1}^{n}\left(v_{i j}-v_{j}^{-}\right)^{2}},
$$

dengan $\mathrm{i}=1,2, . . \mathrm{m}$

f. Menghitung kedekatan relatif terhadap solusi ideal :

$$
C_{i}^{+}=\frac{s_{i}^{-}}{s_{i}^{+}+s_{i}^{-}}, \text {dengan } 0<C_{i}^{+}<1
$$

dan $\mathrm{i}=1,2,3, . ., \mathrm{m}$

keterangan:nilai ci yang lebih besar menunjukkan prioritas alternatif.

g. melakukan peringkatan Alternatif, Alternatif dapat diperingkatkan berdasarkan urutan nilai $C i+$. Dengan alternatif terbaik adalah salah satu yang berjarak terpendek terhadap solusi positifideal dan berjarak terjauh dengan solusi negatif-

\begin{tabular}{|c|c|c|c|c|c|c|c|c|c|c|c|c|c|c|c|}
\hline \multicolumn{16}{|c|}{ Perbandingan Alternatif Supplier } \\
\hline Supplier 1 & & 8 & & & 4 & & & & & 4 & & & & & \begin{tabular}{|l|l|}
9 Supplier 2 \\
\end{tabular} \\
\hline Supplier 1 & 9 & 8 & 6 & 5 & 4 & & & 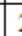 & 3 & 4 & & 6 & & & \begin{tabular}{|l|l|}
9 Supplier 3 \\
\end{tabular} \\
\hline Supplier 1 & 9 & 8 . & 6 & 5 & 4 & & & D. & 3 & 4 & & 6] & & & 9 Supplier 4 \\
\hline Supplier 1 & 9 & 8 & 6 & 5 & 4 & & 2 & 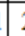 & 3 & & & 6 & & 8 & \begin{tabular}{|l|l|}
9 Supplier 5 \\
\end{tabular} \\
\hline Supplier 2 & \begin{tabular}{l|l}
9 & 8 \\
\end{tabular} & 8 & 6 & 5 & 4 & & & 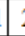 & 3 & 4 & & 6 & & 8 & \begin{tabular}{l|l|}
9 & Supplier 3 \\
\end{tabular} \\
\hline Supplier 2 & 9 & 8 & 6 & 5 & 4 & & 2 & 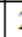 & 3 & 4 & & 6 & & 8 & 9 Supplier 4 \\
\hline Supplier 2 & 9] & 8 & 6 & 5 & 4 & & & 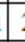 & 3 & 4 & & 6 & & 3 & 9 Supplier 5 \\
\hline upplier 3 & \begin{tabular}{|l|l|l|}
9 & 8 \\
\end{tabular} & 8 & 6 & 5 & 4 & & & & 3 & 4 & & 6 & & 8 & \begin{tabular}{|l|l|}
9 & Supplier 4 \\
\end{tabular} \\
\hline applier 3 & \begin{tabular}{|l|l}
9 & 8 \\
\end{tabular} & 8 & 6 & & T & & & & 3 & 4 & & 6 & & 8 & \begin{tabular}{|l|l|}
9 & Supplier 5 \\
\end{tabular} \\
\hline upplier 4 & & & & & & & & & & & & & & & 9 Supplier 5 \\
\hline
\end{tabular}
ideal.

\section{HASIL DAN PEMBAHASAN}

\subsection{Supplier bahan baku plate}

Terdapat 5 supplier bahan baku kapur aktif yang ada di perusahaan kimia dengan perbandingan alternatif-alternatif sebagai berikut

Gambar 1 Kuesioner Perbandigan antar Alternatif Supplier

\subsection{Kriteria dan subkriteria}

Untuk mengetahui kriteria dan subkriteria ini didasari oleh hasil wawancara dan penelitian terdahulu (Azimifard, Moosavirad, \& Ariafar, 2018) yang kemudian dikonfirmasikan dan dianggap penting oleh perusahaan kimia yaitu :

Tabel 1 Kriteria dan Subkriteria Pemilihan

Supplier

\begin{tabular}{|l|l|}
\hline Kriteria & Sub kriteria \\
\hline \multirow{2}{*}{ Finansial (A) } & Harga penawaran (A1) \\
\cline { 2 - 2 } Kualitas (B) & Kondisi finansial (A2) \\
\hline \multirow{3}{*}{ Pelayanan (C) } & $\begin{array}{l}\text { Kesesuaian spesifikasi (B1) } \\
\text { kualitas (B2) }\end{array}$ \\
\cline { 2 - 2 } Lingkungan (D) & Kapasitas Produksi (C1) \\
\cline { 2 - 2 } & Fetepatan waktu kirim (C2) \\
\cline { 2 - 2 } & $\begin{array}{l}\text { Teknologi pengolahan limbah } \\
\text { (D2) }\end{array}$ \\
\hline \multirow{4}{*}{$\begin{array}{l}\text { Kemampuan } \\
\text { teknis (E) }\end{array}$} & $\begin{array}{l}\text { Reputasi kompetensi Tenaga } \\
\text { kerja Supplier (E2) }\end{array}$ \\
\cline { 2 - 2 } & $\begin{array}{l}\text { Fasilitas produksi supplier } \\
\text { (E3) }\end{array}$ \\
\hline
\end{tabular}

\section{3 kriteria dan subkriteria}

Setelah diketahui kriteria dan subkriteria, Pengisian kuesioner dilakukan oleh responden yaitu Pengisian matriks perbandingan berpasangan yang berdasarkan pertimbangan yang dianggap memahami supplier yang ada. Terdapat 3 responden yang bersasal dari bagian Pengadaan. 


\subsection{Rekap Hasil Kuesioner}

Setelah melakukan penyebaran kuesioner untuk kriteria, subkriteria maka akan dilakukan rekapitulasi terhadap data kuesioner agar dapat mengetahui nilai dan dapat dilakukan pembobotan pada kriteria dan sub kriteria.

Gambar 2 Kuesioner Perbandingan Kriteria untuk mencapai Tujuan

\begin{tabular}{|c|c|c|c|c|c|c|c|c|c|c|c|c|c|c|c|c|}
\hline \multicolumn{17}{|c|}{ Perbandingan Berpasangan Kriteria Pelayanan } \\
\hline Kapasitas & & & & & & & & & & & & & & & & Ketepatan Waktu \\
\hline Produksi & 9 & 8 & 7 & & & 3 & 2 & 1 & 2 & 3 & 4 & & 6 & & 8 & 9 kirim \\
\hline $\begin{array}{l}\text { Kapasitas } \\
\text { Produksi }\end{array}$ & 9 & 8 & 7 & & & 3 & 2 & 1 & 2 & 31 & 4 & 5 & 6 & & & 9 Fleksibilitas \\
\hline $\begin{array}{l}\text { Ketepatan } \\
\text { Waktu kirim }\end{array}$ & 9 & 8 & & & & 3 & & & & 3 & 4 & 5 & 6 & 7 & 8 & 9 Fleksibilitas \\
\hline
\end{tabular}

\subsection{Matriks awal Perbandingan Subkriteria pada Kriteria}

Kriteria Pelayanan $(\mathrm{C})$

$\mathrm{C} 1=$ Kapasitas Produksi

$\mathrm{C} 2=$ Ketepatan waktu kirim

C3 $=$ Fleksibilitas

Kriteria harga

a. Matriks perbandingan berpasangan diperoleh dari penilaian respondeen pada kuesioner yang kemudian di rata-rata dari 3 responden.

Tabel 2 Matriks Awal Perbandingan Berpasangan

\begin{tabular}{|c|c|c|c|}
\hline $\begin{array}{c}\text { Sub } \\
\text { kriteria }\end{array}$ & $\mathrm{C} 1$ & $\mathrm{C} 2$ & $\mathrm{C} 3$ \\
\hline $\mathrm{C} 1$ & 1 & 7,67 & 8,33 \\
\hline $\mathrm{C} 2$ & 0,13 & 1 & 2,33 \\
\hline $\mathrm{C} 3$ & 0,12 & 0,43 & 1 \\
\hline $\begin{array}{c}\text { Jumlah } \\
\text { kolom }\end{array}$ & $\mathbf{1 , 2 5}$ & $\mathbf{9 , 1 0}$ & $\mathbf{1 1 , 6 7}$ \\
\hline
\end{tabular}

b. Bagi masing-masing elemen pada kolom tertentu dengan nilai jumlah kolom tersebut. Hasil tersebut adalah normalisasi matriks antar subkriteria

Tabel 3 Normalisasi Matriks

\begin{tabular}{|c|r|r|r|}
\hline $\begin{array}{c}\text { Sub } \\
\text { Kriteria }\end{array}$ & \multicolumn{1}{c|}{ C1 } & \multicolumn{1}{c|}{ C2 } & \multicolumn{1}{c|}{ C3 } \\
\hline C1 & 0,80 & 0,84 & 0,71 \\
\hline C2 & 0,10 & 0,11 & 0,20 \\
\hline C3 & 0,10 & 0,05 & 0,09 \\
\hline Total & $\mathbf{1 . 0 0 0}$ & $\mathbf{1 . 0 0 0}$ & $\mathbf{1 . 0 0 0}$ \\
\hline
\end{tabular}

c. Setelah didapat hasil normalisasi, hitung vector eigen matriks dengan merata-ratakan jumlah baris dari normalisasi dengan jumlah subkriteria.
Tabel 4 Bobot Subkriteria

\begin{tabular}{|c|c|}
\hline Jumlah baris & Bobot \\
\hline 2,36 & 0,78 \\
\hline 0,41 & 0,14 \\
\hline 0,23 & 0,08 \\
\hline $\mathbf{3 . 0 0 0}$ & $\mathbf{1 . 0 0}$ \\
\hline
\end{tabular}

d. Menghitung rasio konsistensi

Tabel 5 Matriks Awal Dan Bobot Subkriteria

\begin{tabular}{|c|c|c|c|c|}
\hline $\begin{array}{c}\text { Sub } \\
\text { kriteria }\end{array}$ & $\mathrm{C} 1$ & $\mathrm{C} 2$ & $\mathrm{C} 3$ & Bobot \\
\hline $\mathrm{C} 1$ & 1 & 7,67 & 8,33 & 0,78 \\
\hline $\mathrm{C} 2$ & 0,13 & 1 & 2,33 & 0,14 \\
\hline $\mathrm{C} 3$ & 0,12 & 0,43 & 1 & 0,08 \\
\hline
\end{tabular}

e. Kalikan nilai matriks perbandingan awal dengan bobot, didapatkan matriks sebagai berikut:

Tabel 6 Perhitungan Rasio Konsistensi

\begin{tabular}{|c|c|c|c|c|}
\hline $\begin{array}{c}\text { Sub } \\
\text { Kriteria }\end{array}$ & C1 & C2 & C3 & $\begin{array}{c}\text { Jumlah } \\
\text { Baris }\end{array}$ \\
\hline C1 & 0,78 & 1,06 & 0,64 & 2,47 \\
\hline C2 & 0,10 & 0,14 & 0,18 & 0,42 \\
\hline C3 & 0,09 & 0,06 & 0,08 & 0,23 \\
\hline
\end{tabular}

f. Bagi jumlah baris dengan bobot

Tabel 7 Perhitungan Rasio Konsitensi

\begin{tabular}{|c|c|c|c|}
\hline $\begin{array}{c}\text { Sub } \\
\text { kriteria }\end{array}$ & $\begin{array}{c}\text { Jumlah } \\
\text { baris }\end{array}$ & Bobot & Hasil bagi \\
\hline $\mathrm{C} 1$ & 2,47 & 0,78 & 3,172079 \\
\hline $\mathrm{C} 2$ & 0,42 & 0,14 & 3,025512 \\
\hline $\mathrm{C} 3$ & 0,23 & 0,08 & 3,003221 \\
\hline
\end{tabular}

g. Menghitung nilai $\lambda$ maks

$$
\begin{aligned}
\lambda \text { maks } & =(3,172079+3,025512+3,003221) / 3 \\
& =3,066937531
\end{aligned}
$$

h. Menghitung nilai Consistency Index (CI)

$$
\begin{aligned}
\mathrm{CI} & =\frac{\lambda \text { maks }-\mathrm{n}}{n-1} \\
\mathrm{CI} & =(3,066937531-3) /(3-1) \\
& =0,066937531 / 2 \\
& =0,033468765
\end{aligned}
$$

i. Menghitung nilai rasio konsistensi (CR), yaitu membagi CI dengan indeks random (RI). Untuk ordo matriks $\mathrm{n}=3$ maka nilai RI adalah 0,58 .

$$
\begin{aligned}
\mathrm{CR} & =\mathrm{CI} / \mathrm{RI} \\
& =0,033468765 / 0,58 \\
& =0,057
\end{aligned}
$$

Rasio konsistensi sebesar 0,057 karena masih kurang dari batas tolerasi yaitu 0,1 Maka matriks perbandingan berpasangan pada kritera ini 
dikatakan konsisten dan tidak perlu diperbaiki atau diulang.

Tabel 8 Hasil Nilai bobot akhir dari setiap subkriteria

\begin{tabular}{|c|c|c|c|c|}
\hline Kriteria & Nilai Bobot & Subkriteria & Nilai bobot & Bobot Akhir \\
\hline \multirow{2}{*}{$\mathrm{A}$} & \multirow{2}{*}{0,24} & $\mathrm{~A} 1$ & 0,37 & 0,089 \\
\cline { 3 - 5 } & & $\mathrm{A} 2$ & 0,63 & 0,151 \\
\hline \multirow{2}{*}{$\mathrm{B}$} & \multirow{2}{*}{0,34} & $\mathrm{~B} 1$ & 0,83 & 0,282 \\
\cline { 3 - 5 } & & $\mathrm{B} 2$ & 0,17 & 0,058 \\
\hline \multirow{2}{*}{$\mathrm{C}$} & \multirow{2}{*}{0,16} & $\mathrm{C} 1$ & 0,78 & 0,126 \\
\cline { 3 - 5 } & & $\mathrm{C} 2$ & 0,14 & 0,022 \\
\cline { 3 - 5 } & & $\mathrm{C} 3$ & 0,08 & 0,012 \\
\hline \multirow{2}{*}{$\mathrm{D}$} & \multirow{2}{*}{0,23} & $\mathrm{D} 1$ & 0,43 & 0,099 \\
\cline { 3 - 5 } & & $\mathrm{D} 2$ & 0,53 & 0,123 \\
\hline \multirow{2}{*}{$\mathrm{E}$} & \multirow{2}{*}{0,04} & $\mathrm{E} 1$ & 0,53 & 0,021 \\
\cline { 3 - 5 } & & $\mathrm{E} 2$ & 0,43 & 0,017 \\
\hline
\end{tabular}

\subsection{Penentuan Peringkat Supplier dengan Perhitungan TOPSIS}

a. TOPSIS dimulai dengan membangun sebuah matriks keputusan berdasarkan hasil penyebaran kuesioner antara alternatif pada setiap sub kriteria

Tabel 9 Matriks Awal Perbandingan Alternatif

\begin{tabular}{|c|c|c|c|c|c|c|c|c|c|c|c|}
\hline \multirow{2}{*}{ Alternatif } & \multicolumn{10}{|c|}{ Sub Kriteria } \\
\cline { 2 - 13 } & A1 & A2 & B1 & B2 & C1 & C2 & C3 & D1 & D2 & E1 & E2 \\
\hline Sp 1 & 0,21 & 0,23 & 0,26 & 0,28 & 0,13 & 0,14 & 0,29 & 0,31 & 0,32 & 0,23 & 0,41 \\
\hline Sp 2 & 0,43 & 0,10 & 0,40 & 0,22 & 0,19 & 0,14 & 0,14 & 0,10 & 0,27 & 0,10 & 0,17 \\
\hline Sp 3 & 0,12 & 0,50 & 0,10 & 0,19 & 0,26 & 0,24 & 0,13 & 0,19 & 0,12 & 0,26 & 0,18 \\
\hline Sp 4 & 0,19 & 0,13 & 0,04 & 0,11 & 0,11 & 0,29 & 0,19 & 0,15 & 0,06 & 0,21 & 0,15 \\
\hline Sp 5 & 0,04 & 0,04 & 0,20 & 0,20 & 0,32 & 0,18 & 0,25 & 0,25 & 0,23 & 0,19 & 0,10 \\
\hline
\end{tabular}

b. Normalisasikan matriks antar alternatif.

Menggunakan rumus

$$
\begin{aligned}
r_{i j} & =\frac{x_{i j}}{\sqrt{\sum_{i=1}^{n} x_{i j^{2}}}} \\
& =\frac{0,21}{\sqrt{(0,21)^{2}+(0,43)^{2}+(0,12)^{2}+(0,19)^{2}+(0,04)^{2}}} \\
& =0,4
\end{aligned}
$$

Tabel 10 Normalisasi Matriks

\begin{tabular}{|c|c|c|c|c|c|c|c|c|c|c|c|}
\hline \multirow{3}{*}{ Alternatif } & \multicolumn{10}{|c|}{ Sub Kriteria } \\
\cline { 2 - 12 } & A1 ( & A2 & B1 & B2 & C1 & C2 & C3 & D1 & D2 & E1 & E2 \\
\cline { 2 - 11 } & 0,089 & 0,15 & 0,28 & 0,06 & 0,13 & 0,02 & 0,01 & 0,1 & 0,12 & 0,02 & 0,02 \\
\hline Sp 1 & 0,40 & 0,41 & 0,49 & 0,61 & 0,26 & 0,31 & 0,62 & 0,66 & 0,64 & 0,51 & 0,80 \\
\hline Sp 2 & 0,81 & 0,17 & 0,76 & 0,48 & 0,39 & 0,30 & 0,30 & 0,20 & 0,55 & 0,22 & 0,33 \\
\hline Sp 3 & 0,22 & 0,87 & 0,19 & 0,41 & 0,54 & 0,51 & 0,27 & 0,39 & 0,23 & 0,56 & 0,35 \\
\hline Sp 4 & 0,36 & 0,23 & 0,08 & 0,23 & 0,23 & 0,63 & 0,41 & 0,32 & 0,12 & 0,46 & 0,30 \\
\hline Sp 5 & 0,08 & 0,07 & 0,38 & 0,42 & 0,66 & 0,39 & 0,54 & 0,52 & 0,46 & 0,42 & 0,19 \\
\hline
\end{tabular}

c. Membentuk matriks ternormalisasi terbobot maka dilakukan perkalian matriks ternormalisasi dengan bobot tiap subkriteria.

Seperti pada SP 1 dikalikan dengan bobot pada A1

\begin{tabular}{|c|c|c|c|c|c|c|c|c|c|c|c|}
\hline \multirow{3}{*}{ Alternatif } & \multicolumn{11}{|c|}{ Sub Kriteria } \\
\hline & A1 ( & A2 & B1 & B2 & $\mathrm{C} 1$ & $\mathrm{C} 2$ & C3 & D1 & D2 & E1 & E2 \\
\hline & 0,089 & 0,151 & 0,282 & 0,058 & 0,126 & 0,022 & 0,012 & 0,099 & 0,123 & 0,021 & 0,017 \\
\hline Sp 1 & 0,036 & 0,061 & 0,137 & 0,036 & 0,033 & 0,007 & 0,007 & 0,065 & 0,079 & 0,011 & 0,014 \\
\hline Sp 2 & 0,072 & 0,026 & 0,214 & 0,028 & 0,049 & 0,007 & 0,004 & 0,020 & 0,068 & 0,005 & 0,006 \\
\hline Sp 3 & 0,020 & 0,131 & 0,053 & 0,024 & 0,068 & 0,011 & 0,003 & 0,039 & 0,029 & 0,012 & 0,006 \\
\hline Sp 4 & 0,032 & 0,034 & 0,023 & 0,014 & 0,029 & 0,014 & 0,005 & 0,032 & 0,015 & 0,010 & 0,005 \\
\hline Sp 5 & 0,007 & 0,011 & 0,108 & 0,025 & 0,084 & 0,009 & 0,006 & 0,051 & 0,057 & 0,009 & 0,003 \\
\hline
\end{tabular}

$$
\begin{aligned}
\mathrm{SP} 1 \times \mathrm{A} 1 & =0,4 \times 0,089 \\
& =0,036
\end{aligned}
$$

Tabel 11 Matriks Normalisasi Terbobot

d. Menentukan solusi ideal positif $(\mathrm{V}+)$ dan solusi ideal negatif (V-)

Untuk menentukan solusi ideal positif maka dilakukan dengan mencari nilai terbaik sesuai dengan sub kriteria dari seluruh alternatif. Misalkan untuk kolom sub kriteria A1 maka nilai terbaiknya terdapat pada subkriteria SP5 sebesar 0.007 karena semakin kecil harga yang ditawarkan maka semakin baik.

Untuk menentukan solusi ideal negatif dilakukan dengan mencari nilai terburuknya sesuai dengan sub kriteria dari seluruh alternatif., Misalkan untuk kolom sub kriteria A1 maka nilai terbaiknya terdapat pada subkriteria SP1 sebesar 0.036 karena semakin besar harga yang ditawarkan maka semakin tidak baik.

Tabel 12 solusi deal positif (V+) dan Negatif (V-) tiap subkriteria

\begin{tabular}{|c|c|c|}
\hline SubKriteria & $\mathrm{V}+$ & $\mathrm{V}-$ \\
\hline A1 & 0,007 & 0,072 \\
\hline A2 & 0,131 & 0,011 \\
\hline B1 & 0,214 & 0,023 \\
\hline B2 & 0,014 & 0,036 \\
\hline C1 & 0,084 & 0,029 \\
\hline C2 & 0,014 & 0,007 \\
\hline C3 & 0,007 & 0,003 \\
\hline D1 & 0,065 & 0,02 \\
\hline D2 & 0,079 & 0,015 \\
\hline E1 & 0,012 & 0,005 \\
\hline E2 & 0,014 & 0,003 \\
\hline
\end{tabular}

e. Menentukan jarak antara nilai terbobot setiap alternatif terhadap solusi ideal positif $(\mathrm{Si}+)$ dan solusi ideal negatif ( $\mathrm{Si}-$ ).

$$
\begin{aligned}
S_{i}^{+}= & \sqrt{\sum_{j=1}^{n}\left(v_{i j}-v_{j}^{+}\right)^{2}}, \\
& \sqrt{(0.036-0.007)^{2}+\ldots+(0.014-0.014)^{2}}
\end{aligned}
$$




$$
=0.043
$$

$$
S_{i}^{-}=\sqrt{\sum_{j=1}^{n}\left(v_{i j}-v_{j}^{-}\right)^{2}},
$$

$$
\begin{aligned}
& =\sqrt{(0.036-0.0072)^{2}+. .+(0.003-0.003)^{2}} \\
& =0.462169
\end{aligned}
$$

Tabel 13 jarak antara nilai terbobot setiap alternatif terhadap solusi deal positif ( $\mathrm{Si}+$ ) dan Negatif (Si-) tiap subkriteria

\begin{tabular}{|c|c|c|}
\hline Alternatif & $\mathrm{Si}+$ & $\mathrm{Si}-$ \\
\hline $\mathrm{Sp} 1$ & 0,042865 & 0,152687 \\
\hline $\mathrm{Sp} 2$ & 0,040613 & 0,200109 \\
\hline $\mathrm{Sp} 3$ & 0,043590 & 0,142378 \\
\hline $\mathrm{Sp} 4$ & 0,042202 & 0,053264 \\
\hline $\mathrm{Sp} 5$ & 0,019371 & 0,131805 \\
\hline
\end{tabular}

f. Menghitung Nilai kedekatan relatif terhadap solusi ideal didapatkan dari pembagian antara nilai separasi negatif dengan penjumlahan nilai separasi positif dan negatif.

Berikut contoh perhitungan pada PT Krakatau Steel :

$$
\begin{gathered}
C_{i}^{+}=\frac{s_{i}^{-}}{s_{i}^{+}+s_{i}^{-}}, \text {dengan } 0<C_{i}^{+}<1 \\
\frac{0,042865}{0,042865+0,152687}=0,219198
\end{gathered}
$$

Tabel 14 Nilai Preferensi

\begin{tabular}{|c|c|}
\hline Alternatif & Nilai Preferensi (Ci+) \\
\hline Sp 1 & 0,219198 \\
\hline Sp 2 & 0,168712 \\
\hline Sp 3 & 0,234397 \\
\hline Sp 4 & 0,442064 \\
\hline Sp 5 & 0,128137 \\
\hline
\end{tabular}

Dapat di lihat tabel di atas bahwa nilai preferensi terbesar adalah SP 4 dengan nilai 0,442064 .

\section{KESIMPULAN}

1. Terdapat beberapa kriteria dalam menentukan peringkat supplier terbaik yaitu kriteria Kualitas $(0,34)$, finansial $(0,24)$, Lingkungan
(0,23), Pelayanan $(0,16)$, dan Kemmpuan teknis $(0,04)$

2. Sedangkan subkriteria sebagai berikut :

a. Kriteria Finansial : Harga penawaran $(0,089)$ dan Kondisi Finansial $(0,151)$

b. Kriteria Kualitas : Kesesuaian Spesifikasi $(0,282)$ dan Asuransi ketidaksesuaian kualits $(0,058)$

c. Kriteria Pelayanan : Kapasitas Produksi $(0,126)$, Ketepatan waktu kirim(0,022), dan Fleksibilitas(0,012).

d. Kriteria Lingkungan : Proses Produksi $(0,099)$ dan teknologi pengolahan limbah $(0,123)$

e. Kemampuan Teknis : Reputasi kompetensi tenaga kerja supplier $(0,021)$ dan Fasilitas Produksi Supplier $(0,017)$

3. Berdasarkan perhitungan dengan metode AHP dan TOPSIS dengan urutan nilai preferensi terbesar sampai dengan terkecil adalah $\mathrm{Sp} 4$ dengan nilai 0,442064 , Sp 3 dengan nilai 0,234397, SP 1 dengan nilai 0,219198, Sp 2 dengan nilai 0,168712 dan SP 5 dengan nilai0,128137

\section{DAFTAR PUSTAKA}

Azimifard, A., Moosavirad, S. H., \& Ariafar, S. (2018). Selecting sustainable supplier countries for Iran's steel industry at three levels by using AHP and TOPSIS methods. Resources Policy, 30-44.

Chamid, A. A., \& Murti, A. C. (2017). Kombinasi Metode AHP Dan TOPSIS Pada Sistem Pendukung Keputusan. SNATIF (pp. 115-119). Kudus: SNATIF.

Horney, N., Pasmore, B., \& O'Shea, T. (2010). Leadership agility: a business imperative for a VUCA world. People \& Strategy, 32-38.

Hwang, \& Yoon. (1981). Multiple Attribute Decision Making: Methods and Applications. New York: Springer.

Lima Junior, F. R., Osiro, L., \& Carpinetti, L. C. (2014). A comparison between Fuzzy AHP and Fuzzy TOPSIS methods to supplier selection. Applied Soft Computing, 1-16.

Mukherjee, K. (2017). Supplier Selection An MCDA-Based Approach. India: Springer. 
Munier, N., Hontoria, E., \& Jiménez-Sáez, F. (2019). Strategic Approach in MultiCriteria Decision Making A Practical Guide for Complex Scenarios. USA: Springer.

Sa'nchez, A. M., \& Pe'rez, M. P. (2006). Supply chain flexibility and firm performance. Emerald, 681-700.

Saaty, T. L. (1980). The Analytical Hierarchy Process, Planning, Priority Resource Allocation. USA: RWS Publications.

Saaty, T. L. (1990). How to make a Decision : The Analytic Hirarchy Process. European Journal of Operation Research, 9-26.

Saaty, T. L., \& Ergu, D. (2015). When is a Decision-Making Method Trustworthy? Criteria for Evaluating Multi-Criteria Decision-Making Methods. world scientific, 1-17.

Sattar, B. (2016). Challenges Of Globalisation: Leading yourself, your team and organisation to success in a VUCA world. Leadership Excellence Essentials. Sciendo journal, 24-25. 